\title{
One year after head injury a substantial proportion of patients showed neuropsychiatric symptoms
}

\author{
Deb S, Lyons I, Koutzoukis C. Neuropsychiatric sequelae one year after a minor head injury.J Neurol Neurosurg Psychiatry 1998 \\ Dec;65:899-902.
}

\section{Question}

What is the prevalence of neuropsychiatric sequelae 1 year after minor head injury?

\section{Design}

Inception cohort followed up for 1 year.

\section{Setting}

South Glamorgan health district, UK.

\section{Patients}

148 adults $>17$ years of age (median age $40 \mathrm{y}, 66 \%$ men) admitted to hospital after minor head injury between 1 July, 1994 and 30 June 1995. Inclusion criteria were Glasgow Coma Scale score between 13 and 15 and either a period of lost consciousness after the head injury, or radiological or clinical evidence of brain injury. $90 \%$ of patients were followed up for 1 year.

\section{Assessment of prognostic factors}

A questionnaire was devised based on a head injury evaluation chart developed by the European Brain Injury Society for the purpose of collecting data from patients and their relatives on patient's age, sex, date of interview, date of head injury, and an estimate of current alcohol intake.

\section{Main outcome measures}

Scores on the Glasgow Outcome Scale, Edinburgh Rehabilitation Status Scale, Barthel Index, Clinical Interview ScheduleRevised, Psychosis Screening Questionnaire, Behavioural Rating Questionnaire, and Mini Mental State Examination.

\begin{abstract}
Main results
3 patients died during follow up. According to the Glasgow Outcome Scale, 4 of 134 patients (3\%) were severely disabled, 35 $(26 \%)$ were moderately disabled, and $95(71 \%)$ had no disability at 1 year of follow up. A slightly higher percentage of patients (33\%) showed disability according to the Edinburgh Rehabilitation Status Scale. 31 patients (23\%, 95\% CI 17\% to 31\%) scored $<24$ on the Mini Mental State Examination. 23 patients (17\%, CI $11 \%$ to $25 \%$ ) were diagnosed as psychiatric cases according to the Clinical Interview Schedule-Revised and the Psychosis Screening Questionnaire. 74 patients (55\%, CI 46\% to 64\%) manifested any one of the symptoms of post-concussional syndrome according to the Behavioural Rating Questionnaire. The most common behavioural problems noted were irritability (30\%), sleep problems (29\%), impatience (22\%), mood swings $(25 \%)$, tiredness $(22 \%)$, and slowness in thinking $(15 \%)$.
\end{abstract}

\section{Conclusion}

One year after head injury a substantial proportion of patients showed neuropsychiatric symptoms.

Source of funding: The Welsh Office.

For correspondence: Dr S Deb, Division of Psychological Medicine, University of Wales College of Medicine, Heath Park, CardiffCF4 4XN, UK.E-mail <deb@cardiff.ae.uk>.

\section{Commentary}

The annual incidence of head injury in the UK is 300 per $100000 .{ }^{1}$ The majority of these are minor. The consequence to the patient, family, and society is anything but minor and has led to increased attention given to this group. ${ }^{2}$

There are considerable methodological problems in this area of research which Deb et al highlight. The first is inconsistent nomenclature. Head injury and brain injury are not interchangeable The Brain Injury Association and the American Congress of Rehabilitation Medicine recommend the term mild traumatic brain injury to be distinguished from head injury (where there is cranial or cranial adnexal trauma). ${ }^{3}$ The inclusion criteria used by Deb et al admit skull fracture (moderate to severe head injury) and cerebral haemorrhage or contusion (moderate to severe brain injury). Ascertainment is difficult and unreliable using current National Health Service records. ${ }^{2}$ This was apparent in our own experience when the annual incidence for head and brain injury categorised using $I C D$, in the health authorities central database, dropped significantly with the changes from ICD-9 to 10 .

Choice of clinical instruments can also be difficult in this patient group. The frontal lobes of the brain are particularly vulnerable to the effects of closed head injury. Unfortunately, the Mini Mental State Examination does not detect the resulting dysexecutive function.

Post-concussional syndrome contains non-specific symptoms with considerable overlap of expression in the general population without head injuries. This emphasises the need for a control group which is absent in this study. The index group could be compared with their premorbid state, with their own state over time, or with a non-head injured, age matched control group. This is important when one quarter of the groups were $>65$ years of age and more vulnerable to other confounding pathology.

Deb et al have shown an association of neuropsychiatric symptoms with head injury but not cause and effect. The implication of this study for clinical practice is to be aware that head injury and brain injury are not synonomous and that minor (mild) head injury may mask moderate to severe brain injury in those whose recovery appears delayed or incomplete.

Kieran O’Driscoll Rathbone Hospital Liverpool, UK

1 Barnes M, Eames P, Evans C, et al. Rehabilitation after traumatic brain injury: working party report of the British Society of Rehabilitation Medicine. London: Royal College of Physi-

2 Levin HS, Eisenberg HM, Benton AL. Mild head injury. Oxford: Oxford University Press, 1989.

3 Horn LJ, Zasler ND. Medical rehabilitation of traumatic brain injury. Philadelphia: Hanley \&
Belfus Inc, 1996 . 